\title{
CONSUMO DE SUPLEMENTOS NUTRICIONAIS POR PRATICANTES DE EXERCÍCIOS FÍSICOS EM ACADEMIAS
}

\section{USE OF NUTRITIONAL SUPPLEMENTS BY SUBJ ECTS ENROUED IN PHYSICAL FITNESS PROGRAMS}

\author{
Luciene Pereira da ROCHA \\ Maria Vanessa Lott PEREIRA²
}

\begin{abstract}
RESUMO
Este trabalho teve por objetivo verificar o consumo de suplementos em indivíduos praticantes de exercícios físicos em academias de Niterói e São Gonçalo (RJ). O grupo de estudo (GE) constituiu-se de 160 indivíduos (10 por academia), selecionados ao acaso e que responderam a um questionário. As academias foram escolhidas de acordo com a localização e receptividade para a realização do levantamento. Verificou-se que 51 indivíduos (32\%) faziam uso de algum tipo de suplemento e 109 não (68\%). O grupo de usuários de suplementos compunha-se por indivíduos entre 20 e 30 anos, sendo 35 do sexo masculino e 16 do feminino; 17 praticantes de musculação, 15 de ginástica, 10 de várias modalidades e 9 de ginástica e musculação. Vinte oito pessoas usavam um tipo de suplemento e 23 mais de um, sendo que dois indivíduos usavam seis tipos diferentes. Os praticantes de musculação usavam preferentemente aminoácidos e proteínas, além de produtos de composição mista, bem como "energéticos" e "estimulantes". Os praticantes de ginástica usavam mais suplementos deste último tipo, além de vitaminas e minerais. Os praticantes de ginástica associada à musculação e várias modalidades usavam praticamente todos os tipos de suplemento. A maioria dos usuários consumia suplementos diariamente (82,3\%) sendo a dose variada, muitos relatando o uso recomendado no rótulo. Trinta e dois participantes relataram que receberam orientação para o consumo dos suplementos. As autoras discutem os resultados encontrados e apresentam uma breve revisão sobre os efeitos do uso de suplementos para a melhoria da saúde ou do desempenho físico.
\end{abstract}

Termos de indexação: suplementação alimentar, exercício.

\begin{abstract}
This is a survey on the use of nutritional supplements by subjects enrolled in physical fitness schools in Niterói and São Gonçalo (RJ). The study group had 160 subjects (10 for school), selected at random, who answered a questionnaire. Schools were chosen occording to localization and receptivity to answering the questions. The results showed that 51 subjects (32\%) were using some kind of supplement and 109 were not (68\%). The supplement user

\footnotetext{
(1) Acadêmica do Curso de Graduação em Nutrição da Universidade Federal Fluminense, Niterói, RJ.

(2) Professora do Departamento de Nutrição e Dietética da Faculdade de Nutrição da Universidade Federal Fluminense, Rua São Paulo, 30, $4^{\circ}$ andar, 24015-110, Niterói, RJ.
} 
group (SUG) was compounded by subjects between the ages of 20 and 30 years, 35 men and 16 women, 17 of them engaged in strength physical exercise, 15 in gymnastics, 9 in both and 10 in various types of physical exercises. The SUG had 28 subjects who were using one kind of supplement and 23 that were using two or more; two subjects used six types of supplements. The subjects undergoing strength physical exercise preferred to use not only amino acids and protein supplements, but also "energizing products" and "stimulants". The subjects enrolled in gymnastics preferred the latter products, but used vitamins and minerals too. The others used all sorts of supplements. Many subjects (82.3\%) of the SUG used the supplements daily at different doses. Thirty-two subjects related that they had received orientation in the use of supplements. The authors discuss the results presented and make a short review of the effects of supplements on physical performance and health.

Index terms: supplementary feeding, exercise.

\section{INTRODUÇÃO}

A busca pelo melhor condicionamento físico e pela manutenção da saúde tem levado muitas pessoas à prática de várias modalidades de exercícios físicos em academias e algumas vezes a procura de meios rápidos para alcançar seus objetivos.

É provável que a crescente divulgação pela mídia de diferentes suplementos e seus efeitos benéficos sobre a saúde, tenha influenciado $\mathrm{o}$ aumento da demanda destes produtos (MARINHO, 1994; GESSONI, 1995).

Na área da medicina esportiva, apesar de algumas controvérsias, pesquisas realizadas com atletas de elite demonstraram que alguns suplementos podem minimizar o desgaste causado por exercícios intensos, repor as perdas ou mesmo melhorar sua performance (KREIDER et al., 1993; CARDOSO, 1994b). No entanto, pouco se tem estudado sobre o uso e o efeito de suplementos em indivíduos desportistas ou mesmo em sedentários.

Este trabalho teve por proposta principal, verificar o consumo de suplementos em um grupo de indivíduos praticantes de exercícios físicos em academias, identificando o perfil do usuário, os suplementos usados e algumas características sobre seu uso.

\section{MATERIALEMÉTODOS}

O levantamento foi realizado de março a junho de 1995 através de questionários (Anexo I) aplicados em um grupo de estudo (GE) constituído por indivíduos praticantes de exercícios físicos em 16 academias, sendo 13 no município de Niterói
(RJ) e 3 em São Gonçalo (RJ). Os participantes (10 sujeitos por academia) foram escolhidos ao acaso e as academias foram selecionadas de acordo com a facilidade de localização e receptividade por parte da administração para a realização do levantamento.

\section{Ca racterização do grupo de estudo}

O GE constituiu-se de 160 indivíduos, 88 do sexo masculino e 72 do sexo feminino, com idades entre 13 e 47 anos, sendo 89,4\% menores de 30 anos. Apresentavam curso superior concluído ou em andamento 38,7\%; com $2^{\circ}$ grau completo ou incompleto $50,7 \%$; cursando o $1^{\circ}$ grau $8,1 \%$ e não informaram a escolaridade 2,5\%. Quanto à ocupação, verificou-se que $25,6 \%$ eram profissionais liberais, $25,0 \%$ estudantes, $18,1 \%$ prestadores de serviços, $13,8 \%$ desempenhavam outras funções e 17,5\% não informaram.

O objetivo da prática do exercício era principalmente "a busca do condicionamento físico" e a "hipertrofia muscular". Em menor freqüência foram citados “o emagrecimento", "prazer” e "necessidade da profissão”.

Cento e vinte e cinco indivíduos (78\%) nunca receberam orientação de um nutricionista e 35 já foram atendidos alguma vez. No entanto, $70 \%$ dos participantes gostariam de ter orientação de um profissional com objetivo de "saber mais sobre alimentação", "emagrecer” e "aumentar a massa muscular".

Neste levantamento, o termo suplemento, foi entendido como "determinado produto comercial, com composição química variável, consumido como 
estimulante ou com finalidade de satisfazer alguma necessidade fisiológica, melhorar o desempenho e o desenvolvimento físico ou reverter um estado conhecido de deficiência nutricional”’3.

Para fins práticos, os diferentes suplementos citados pelos participantes, foram divididos em seis grupos, de acordo com sua composição. As informações sobre a composição química dos produtos foram obtidas nos rótulos, folhetos dos fabricantes ou tabelas de composição química dos alimentos (FRANCO, 1991).

\section{Gruposde Suplementos}

Grupo I. Produtos com composição predominante em aminoácidos e proteínas.

Grupo II. Produtos com predominância em glicídios.

Grupo III. Produtos à base de vitaminas ou minerais.

Grupo IV. Produtos mistos, ou seja, com proteínas, glicídios, lipídios, vitaminas e minerais.

Grupo V. Produtos à base de hormônios.

Grupo VI. Produtos cuja composição não foi identificada ou não se enquadrava em nenhum dos grupos acima. Foram classificados como outros. No levantamento foram citados como "queimadores de gordura”, “energizantes”, “estimulantes”, etc.

\section{RESULTADOS}

Dos 160 componentes do GE, 51 indivíduos, ou seja, $32 \%$ faziam uso de algum tipo de suplemento e 109 não (68\%).

O grupo de usuários de suplementos (GUS) eraconstituído, em sua maioria, por indivíduos na faixa de 20 a 30 anos de idade, sendo 35 do sexo masculino e 16 do feminino. Quanto ao tipo de exercício, 17 deles faziam musculação, 15 faziam ginástica, 10 várias modalidades como: natação, capoeira ou judô e 9 faziam ginástica e musculação.

Quando foi associado o número de indivíduos usuários de suplementos com a quantidade dos diferentes suplementos usados por eles e o tipo de exercício praticado, verificou-se que 28 indivíduos faziam uso de um tipo de suplemento, sendo 9 praticantes de musculação, 8 de ginástica, 5 de ginástica associada à musculação e 6 de várias modalidades de exercícios. Quinze faziam uso de 2 a 3 tipos de suplementos, sendo 2 praticantes de musculação, 7 de ginástica, 3 de ginástica e musculação e 3 de vários tipos de exercícios. Dos 8 indivíduos que faziam uso de 4 a 6 tipos de suplementos diferentes, 6 praticavam musculação, um ginástica e musculação e o outro vários tipos de exercícios.

Como foi verificado que parte dos usuários consumiam mais de um tipo de suplemento, foi elaborada a Tabela 1 que apresenta quantas vezes um produto foi citado pelos praticantes das diferentes modalidades de exercícios. A maioria consumia os suplementos diariamente (82,3\%) ou de 2 a 3 vezes por semana $(17,7 \%)$. A dose utilizada era diversificada, pois muitos relataram que utilizavam a recomendada no rótulo do produto ou utilizavam como convinha a eles. Alguns não informaram a dose usada.

Verificou-se que o tempo de uso dos suplementos concentrava-se principalmente nas faixas de um a seis meses (33,3\%), de seis meses a um ano $(37,2 \%)$ e mais de um ano $(15,7 \%)$.

Tabela 1. Número de citações por grupo de suplementos, conforme o exercício praticado.

\begin{tabular}{|c|c|c|c|c|c|}
\hline \multirow{2}{*}{$\begin{array}{l}\text { Grupo de } \\
\text { suplementos }\end{array}$} & \multicolumn{5}{|c|}{ Tipos de exercícios físicos } \\
\hline & Musculação & Ginástica & Ginástica e musculação & Vários & Total \\
\hline $\mathrm{I}$ & 18 & 0 & 4 & 3 & 25 \\
\hline II & 1 & 1 & 0 & 2 & 4 \\
\hline III & 3 & 10 & 2 & 3 & 18 \\
\hline IV & 11 & 2 & 4 & 4 & 21 \\
\hline V & 1 & 0 & 0 & 0 & 1 \\
\hline VI & 10 & 12 & 5 & 6 & 33 \\
\hline Total & 44 & 25 & 15 & 18 & 102 \\
\hline
\end{tabular}

(3) Nota do autor. 
Trinta e quatro componentes disseram que alcançaram o efeito desejado, 15 disseram que não e 2 que ainda não. Alguns indivíduos relataram que além do efeito desejado obtiveram também outros benefícios como: "mais disposição e resistência" e "mais saúde e confiança em si mesmos". No entanto, outros afirmaram que tiveram "problemas renais e hepáticos”, “diminuição do desempenho sexual”, “tonteira, enjôos, irritação insônia e acne”, etc.

Dos 51 usuários de suplementos, 32 disseram ter recebido alguma orientação para esta prática. Treze deles receberam de profissionais de saúde ( 9 de médicos e 4 de nutricionistas) e os demais de "instrutores", "amigos", "leitura sobre o assunto", etc.

Das 16 academias escolhidas para este levantamento, uma apresentou 9 usuários de suplementos (entre os 10 pesquisados), duas tinham 6 usuários, uma apresentou 5 e as demais 4 ou menos.

De forma geral, os membros do GUS entendiam que os suplementos "completavam a alimentação", "promoviam a saúde”, "evitavam o desgaste físico", "permitiam o ganho de massa muscular" e dependendo do produto usado, causavam "emagrecimento" e os usavam para atender a um destes propósitos.

Quando foi perguntado aos participantes do GUS se os mesmos conheciam a finalidade do suplemento que usavam, um não respondeu, 7 responderam que não conheciam e 43 responderam que sim. Destes 43 apenas dois souberam dizer com exatidão qual era a finalidade do produto.

Dos 160 componentes do que participaram deste levantamento, 109 não faziam uso de suplementos e quando perguntados se já usaram, se usariam e porque, verificou-se que $67 \%$ destes não usaram anteriormente e nem usariam suplementos e justificaram suas respostas por "não gostar”, "não ter havido necessidade", "por terem uma alimentação suficiente”, etc.

Outros sujeitos (14,7\%), relataram que não usaram mas que usariam por "curiosidade" ou "por necessidade de emagrecer" ou mesmo "para aumentar a massa muscular”.

Por fim 18,3\% daqueles indivíduos que não usavam suplementos na ocasião do levantamento, responderam que já fizeram uso de produtos desta natureza. Porém, quando questionados se voltariam a usar, uma não respondeu, 5 disseram que sim e 14 disseram que não. Estes últimos justificaram suas respostas informando que "não obtiveram resultados”, "que os produtos são muito caros", "que fazem mal à saúde”. Já aqueles que responderam que voltariam a usar, justificaram-se dizendo que se quiserem "melhorar seu rendimento" ou "aumentar a massa muscular" teriam que fazer uso novamente.

\section{DISCUSSÃO}

Os resultados deste levantamento demonstraram que aproximadamente $30 \%$ dos indivíduos que responderam ao questionário usavam algum tipo de suplemento, ocorrendo casos de consumo de até 6 tipos diferentes por uma mesma pessoa. Relatos sobre o uso de suplementos por atletas de elite de várias modalidades esportivas têm sido citados na literatura específica (HAYMES, 1991; KREIDER et al.,1993; CARDOSO, 1994b), porém poucos trabalhos apresentam dados em indivíduos esportistas ou na população em geral.

HAYMES (1991) indica que nos Estados Unidos, mais de $50 \%$ das mulheres maratonistas ou triatletas de elite, consomem algum tipo de suplemento vitamínico ou de minerais. CARDOSO (1994b) também relata dados de uma pesquisa australiana onde $75 \%$ de nadadores, halterofilistas e ciclistas usavam suplementos, enquanto que era utilizado por menos de $32 \%$ dos participantes de voleibol, futebol ebeisebol.

Na população em geral, há citações (CARDOSO,1994b) indicando que 40 a $67 \%$ da população americana e $47 \%$ da australiana usam alguma forma de suplemento. HAYMES (1991) relatou que $30 \%$ dos participantes de maratonas (não atletas de elite) usavam suplementos diariamente. Portanto, a freqüência de consumo encontrada neste GE não representa um dado discrepante.

Neste levantamento, foi observado que os indivíduos praticantes de musculação faziam mais uso de suplementos a base de aminoácidos e proteínas. Artigos publicados em revistas factuais, folhetos e propagandas de alguns produtos, afirmam que suplementos de aminoácidos são úteis para 
halterofilistas e fisioculturistas, pois ajudam a driblar a fadiga e aumentar a massa muscular (JÚNIOR \& BORELLI, 1994). No entanto, dados da literatura científica quanto às necessidades protéicas em praticantes de exercícios físicos, bem como, os possíveis efeitos ergogênicos da ingestão de aminoácidos e proteínas para atletas têm demonstrado resultados conflitantes (LEMON \& PROCTOR, 1991; TARNOPOLSKY et al., 1992; CARDOSO, 1994a; LEMON, 1996).

Um problema básico para a interpretação de resultados de diferentes trabalhos, parece ser o entendimento sobre que valores de ingestão são considerados normais ou recomendados. A Organizacão Mundial da Saúde, cujo informe sobre recomendações nutricionais tem sido considerado como referência em vários países, apesar de não objetivar o estudo em atletas, estipula como recomendação de proteínas um nível seguro de ingestão expresso em $\mathrm{g} / \mathrm{kg}$ de massa corporal para adultos sadios em atividade moderada. O que é ressaltado, no entanto, é que dietas "normais" que atendem às recomendações energéticas, têm em geral de 10 a $15 \%$ do valor energético total (VET) proveniente das proteínas (ORGANIZACIÓN..., 1985). A quantidade de proteínas destas dietas facilmente supera as recomendações expressas em g/kg de massa corporal e são, mesmo assim, consideradas "normais". Para atletas, cujas necessidades energéticas são inegavelmente superiores, há conseqüentemente um consumo de proteínas ainda maior.

Vários autores tem sugerido que a ingestão de proteínas em torno de 15\% do VET parece ser o suficiente para atender às necessidades de desportistas e atletas e que há poucas evidências científicas que justifiquem um consumo superior visando aumentar a massa muscular (McARDLE et al., 1992; KREIDER et al., 1993; LEMON, 1996). No entanto não existe vantagens e sim alguns efeitos indesejáveis em aumentar a ingestão protéica acima de $2 \mathrm{~g} / \mathrm{kg}$ de peso corporal (ODRIOZOLA, 1988).

Em atletas de resistência, por outro lado, a suplementação com aminoácidos de cadeia ramificada (AACR), parece exercer um efeito benéfico sobre a fadiga, melhorando a performance do atleta. Este fato pode ser explicado, pois a atividade física de longa duração aumenta a captação e a oxidação muscular dos AACR com conseqüente redução dos seus níveis sanguíneos. Esta redução desequilibra a relação triptofano/ AACR, favorecendo a entrada do triptofano no cérebro, o que aumenta a síntese de serotonina. Sabese que a serotonina é um neurotransmissor capaz de induzir o sono e diminuir a excitabilidade neuromotora (KREIDER et al., 1993; CARDOSO, 1994b), daí a reposição com AACR ser considerada interessante.

Além de suplementos protéicos, muitos desportistas relataram uso de produtos mistos, ou seja, contendo proteínas, glicídios, lipídios, vitaminas e minerais. Produtos com este tipo de composição são, em geral, de fácil preparo e apresentam alta concentração de nutrientes em pouco volume, podendo ser úteis para reposição energética e de nutrientes de forma rápida.

Nesta pesquisa, muitos praticantes de ginástica usavam suplementos classificados como outros (guaraná, lecitina, carnitina, etc.), vitaminas e minerais. Estes indivíduos estavam em busca do emagrecimento e de um melhor condicionamento físico e não tinham como prioridade o aumento da massa muscular. Considerando que dietas hipoenergéticas consumidas com finalidade de emagrecimento tendem a ser deficientes em micronutrientes, o uso de suplementos de minerais e vitaminas poderia ser justificado. No entanto, não foi feito levantamento de consumo alimentar dos participantes para verificar essa afirmativa. Por outro lado, não há comprovação científica dos efeitos potencializadores do desempenho físico com o uso de vitaminas e minerais em indivíduos cujas dietas são adequadas (HAYMES, 1991).

O grupo de suplementos classificados como outros foi o mais citado pelo GUS, bem como seu uso foi bem distribuído por todo tipo de modalidade de exercício. Neste grupo inclui-se suplementos como guaraná, lecitina, ginseng, etc., cuja composição química não se enquadrava em nenhum outro ou era desconhecida. Para suportar uma discussão mais detalhada sobre os seus efeitos seria necessário um trabalho diversificado de revisão da literatura, o que foge aos objetivos deste levantamento. Pode-se ressaltar apenas que, o uso dos 
chamados fat burners, especialmente a carnitina um tipo de aminoácido sintetizado naturalmente pelo organismo e essencial para a oxidação dos ácidos graxos - não garantem a queima de gordura em maior quantidade, nem o emagrecimento (COWART, 1992; GESSONI, 1995).

Apesar da literatura apresentar controvérsias e indicar, de forma geral, que os efeitos dos suplementos nem sempre são positivos, muitos dos participantes deste levantamento informaram que alcançaram o efeito desejado. É difícil comentar esta afirmativa, pois não houve um acompanhamento destes desportistas para avaliar, de fato, os acontecimentos. É possível que estas afirmações estejam pautadas em bases subjetivas e não em controles biométricos ou de outra ordem, necessários para tais conclusões.

Verificou-se neste estudo a necessidade de se ampliar as pesquisas sobre o consumo de suplementos, esclarecendo conceitos e unificando protocolos para facilitar a interpretação de resultados sobre o assunto.

\section{REFERÊNCIAS BIBLIOGRÁFICAS}

CARDOSO, M.A. Proteínas ou aminoácidos adicionais na dieta de atletas? Nutrição Enteral $e$ Esportiva, Rio de Janeiro, v.3, p.11-12, abr. 1994a.

CARDOSO, M.A. Suplementação dietética nos esportes. Nutrição Enteral e Esportiva, Rio de Janeiro, v.4, p.4-8, ago, 1994b.

COWART, V.S. Dietary Supplements: alternatives to anabolic steroids? The Physician and Sports Medicine, Minneapolis, v.20, n.3, p.189-198, 1992.

FRANCO, G. Tabulação de composição química dos alimentos. 9.ed. Rio de Janeiro : Atheneu, 1991. p.154-155, 157, 159.

GESSONI, R. Fat burners: será que funcionam? Boa Forma, São Paulo, v.10, n.6, p.93-95, 1995.
HAYMES, E.M. Vitamin and mineral supplementation to athletes. International Journal of Sports Nutrition, Champaign IL, v.1, n.1, p.146-169, 1991.

JÚNIOR, L.S., BORELLI, M. Você pergunta: suplementos esportivos. Forma Física, São Paulo, v.2, n.22, p.46-48, 1994.

KREIDER, R. B., MIRIEL, V., BERTUN, E. Amino acid supplementation and exercise performance. Sports Medicine, Auckland, v.16, n.3, p.190209, 1993.

LEMON, P.W.R., PROCTOR, D.N. Protein intake and athletes performance. Sports Medicine, Auckland, v.12, n.5, p.313-325, 1991.

LEMON, P.W.R. Is increased dietary protein necessary or beneficial for individuals with physical active lifestyle? Nutrition Reviews, New York, v.54, n.4, p.S169-S175, 1996.

MARINHO, A. O Globo, Rio de Janeiro, out. 1994. Caderno Jornal da Família.

McARDLE, W.D., KATCH, F.I., KATCH, V.L. Fisiologia do exercício: energia, nutrição e desempenho humano. 3.ed. Rio de Janeiro : Guanabara Koogan, 1992. p.17.

ODRIOZOLA, J.M. Nutrición y desporto. Madrid: Ediciones de la Universa, 1988.

ORGANIZACIÓN MUNDIAL DE LA SALUD. Necessidade de energia y proteinas. Ginebra, 1985. 220p. (Série de Informes Técnicos, 724).

TARNOPOLSKY, M.A., ATKISON, S.A., MacDOUGALL, J.D., CHESLEY A., PHILLIPS, S., SCHWARCZ, H.P. Evaluation of protein requirements for trained strength athletes. Journal of Applied Physiology, Bethesda, v.73, n.5, p.1986, 1992.

Recebido para publicação em 1 de dezembro de 1995 e aceito em 11 de agosto de 1997. 


\section{ANEXO 1}

Questionário $\mathbf{n}^{\mathrm{G}}$

Academia:

Dados pessoais

Nome:

Idade

Scxo: Fem. ( ) Masc. ()

Escolaridade:

Profissão:

Modalidade

Musculaçăo ( )

Ginástica localizada ( )

Ginástica aeróbica ()

Outros ( )

Qual?

Turno: Manhă ( )

larde ()

Noite ( )

\section{Periodicidade}

3 vezes na semara( )

2 vezes na semanas ()

todos os dias ( )

Duração do exercício:

Pratica há quanto tempo?

Qual o seu objetivo?

\section{Questionário}

1) Você faz uso de algum tipo dè produto/suplemento?

$$
\operatorname{sim}()
$$

Por quê?
Năo( ) 1.a) Você já fez uso de algum tipo de produto/suplemento?

$$
\begin{aligned}
& \text { Sim ( ) Nâo( ) } \\
& \text { Por quê? }
\end{aligned}
$$

1.b) Você pretende fazer uso de algum tipo de produlo stuplamento?

$\operatorname{Sim}() \quad$ Não ()
Por quê?

2) Qual(is) o(s) produlo(s) que usa (usou)?

3) Usa (usou) em que periodjcidade?

Diária ( )

1 vez na scmana ( )

2 ou 3 vezes na semana ()

Outros:

4) Usa (usou) em que dose?

5) Usa há quanto tempo? (Usou por quanto tempo?)

6) O que levou você a usar?

7) Vocế sabe (sabia) qual (a) finalidade do produto/suplemento? $\operatorname{sim}()$ Não( ) Qual?

8) Voce obteve o efeito desejado?

$$
\text { Sim ( ) Não( ) Ainda nầo( ) }
$$

9) Vocć obteve algum outro beneficio?

$$
\operatorname{Sim}() \text { Não( }) \text { Qual? }
$$

10) Você apresentou algum problema?

$$
\text { Sim ( ) Não( ) Qual? }
$$

11) Você recebeu alguma orientação para usar o produto/ suplemento?

$$
\text { Sim ( ) Não( ) De quen? }
$$

12) Você já recebela alguma orientação de um protissional de nutrição?

Sim ( ) Não( )

13) Gostaria de receber?

$$
\text { Sim( ) Năo( ) }
$$$$
\text { Com que objetivo? }
$$ 